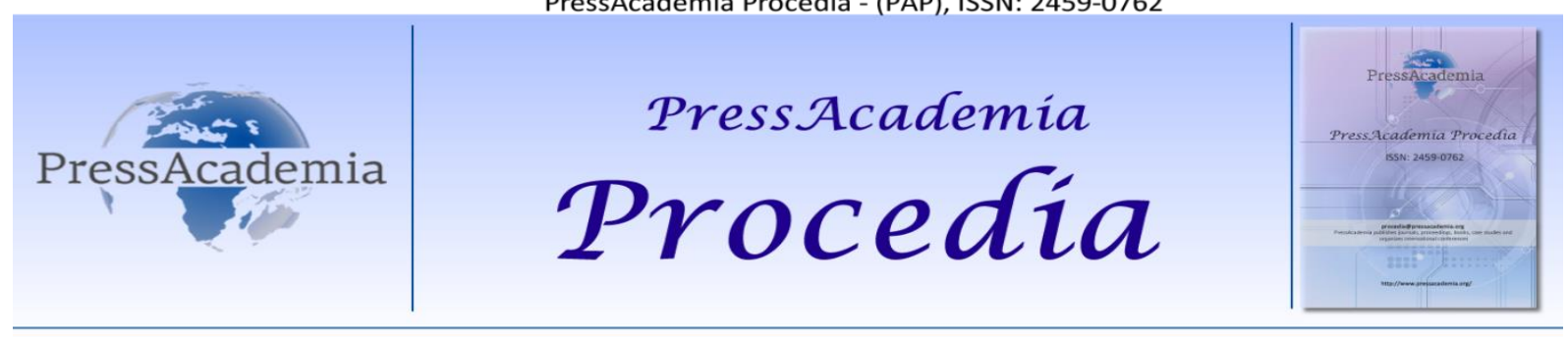

Global Business Research Congress (GBRC), May 24-25, 2017, Istanbul, Turkey

\title{
A QUALITATIVE RESEARCH ON THE DETERMINATION OF THE RELATIONSHIP BETWEEN PERCEIVED ORGANIZATIONAL SUPPORT AND BUSINESS STRESS OF WOMEN WORKIING IN MALE-DOMINATED OCUPPATIONS
}

\author{
DOI: 10.17261/Pressacademia.2017.630 \\ PAP- GBRC-V.3-2017(56)-p.548-553 \\ Ceren Giderler ${ }^{1}$, Zehra Yeni ${ }^{2}$ \\ ${ }^{1}$ Dumlupınar Üniversitesi, iïBF, İşletme Bölümü. ceren.giderler@dpu.edu.tr \\ 22Dumlupınar Üniversitesi, IiBF, İnsan Kaynakları Yönetimi Bölümü. zehraayeni@gmail.com.
}

To cite this document

Giderler, C., Z. Yeni, (2017). A qualitatıve research on the determınatıon of the relatıonshıp between perceived organızatıonal support and busıness stress of women working in male-domınated ocuppatıons. PressAcademia Procedia (PAP), V.3, p.548-553.

Permemant link to this document: http://doi.org/10.17261/Pressacademia.2017.630

Copyright: Published by PressAcademia and limited licenced re-use rights only.

\begin{abstract}
The purpose of this study is to determınatıon of the relatıonshıp between perceived organızatıonal support and busıness stress of women working in male-dominated ocuppations. First varaible is perceived organizational support and the second varaible is business stress which were included in the study. Content analysis and descriptive analysis methods were used in the research from qualitative research methods. Data were collected with purposeful sampling method. The research population is composed of female engineers in the private sector in Kütahya. The data were collected with the question form which is created according to the literature. As a result of the research, it was determined that there is a relationship between perceived organizational support and work stress.
\end{abstract}

Keywords: Perceived organizational support, business stress, famale-male ocuppations.

JEL Codes: M10, M14, D23

\section{ERKEK EGEMEN IŞLERDE ÇALIŞAN KADINLARIN ALGILADIKLARI ÖRGÜTSEL DESTEK ILE iş STRESi ARASINDAKI iLIŞKININ BELIRLENMESINE YÖNELIK NITEL BİR ARAŞTIRMA}

\section{ÖZET}

Bu çalışmanın amacı erkek egemen mesleklerde çalışan kadın çalışanların algıladıkları örgütsel destek ile iş stresi arasındaki ilişkiyi belirlemektir. Araştırmanın ilk değişkeni algılanan örgütsel destek ikinci değişkeni ise iş stresidir. Araştırmada nitel araştırma yöntemlerinden içerik analizi ve betimsel analiz yöntemleri kullanılmıştır. Amaçı̈ı̈rnekleme yöntemi ile veriler toplanmıştır. Araştırmanın evrenini Kütahya’ da bulunan özel sektördeki kadın mühendisler oluşturmaktadır. Veriler literatüre bağlı olarak oluşturulan soru formu yardımıyla toplanmıştır. Araştırma sonucunda algılanan örgütsel destek ile iş stresi arasında ilişkinin olduğu tespit edilmiştir.

Anahtar Kelimeler: Algılanan örgütsel destek, iş stresi, kadın-erkek işi

JEL Kodları: M10, M14, D23 


\section{GíRiş}

Sosyal bilimler alanında araştırma yapan bilim insanlarının ve iş dünyasında yönetici pozisyonunda bulunan yöneticilerin çalışanlarına iş ve örgütleriyle bağlılık oluşturmaları için neler yapmaları gerektiğine yönelik sorular sormaları çalışmalarının başlangıcını oluşturmalıdır. Büyük beklentiler çağı olarak ifade edilen günümüz iş dünyasında, toplum ve çalışanlar örgütlerden sürekli olarak artan bir beklentiye sahiptirler (McMillan ve Albrecht, 2010: 2001). Bu beklentiyi karşılayabilmek için örgütlerin çalışanlarına uygun fiziksel ve psikolojik ortamı hazırlamaları gerekmektedir. Temeli sosyal mübadele kuramına dayanan örgütsel destek; çalışanın kendisine değer verildiğini ve örgütün desteğinin arkasında olduğunu hissettiği, iyi ve kötü günlerini paylaşacağı insanların yanında olduğunu bildiği bir ortamı çalışanına sunmasına yönelik beklentilerin karşılaması için psikolojik ortamın oluşturmasına destek vermektedir. Çalışanın algıladığı bu pozitif algının karşılığı ise çalışanın içten ve örgüt için beklenenden daha fazla çalışmasıdır. Sadece çalışanın örgütten beklentisi değil aynı zamanda örgütün de çalışanlarından bazı beklenti ve istekleri bulunmaktadır. Fakat iş ve iş dışı dünyanın istediği beklentiler bazı zamanlarda çalışanın tahammül sınııını zorlamaktadır. Bu beklenti ile başa çıkamayan çalışan kendisini yetersiz hissederek stres seviyesini artırmaktadır. Bu durumda; çalışanın örgütün beklentileri altında ezilmemesi, yetersizlik hissine kapılmaması ve mesleki başarısızlık göstermemesi için çalışanın örgütsel desteğe ihtiyacı olacaktır. Özellikle erkek işi olarak ifade edilen meslek gruplarında çalışan kadınların kendilerini yetersiz hissetmeleri daha yüksek, tahammül sınırlanın daha düşük olduğu göz önüne alındığında örgütsel desteğin erkek egemen mesleklerde çalışan kadınlar için daha önemli olduğunu söyleyebiliriz.

\section{LITERATÜR INCELEMESI}

Çalışmanın bu bölümünde örgütsel destek, iş stresi, kadın işi-erkek işi kavramları ve hakkında örgütsel destek ile iş stresi arasındaki ilişki hakkında bilgi verilmektedir. Algılanan örgütsel destek ilk olarak 1986 yılınsa Eisenberger ve arkadaşları tarafından çalışımıştır. Algılanan örgütsel destek, örgüt değerlerinin çalışanların iyiliğini, esenliğini, mutluluklarını artırıcı faktörleri dikkate alarak bir kurum kültürü oluşturmak olarak tanımlanmıştır (Eisenberger vd., 1986, 501). Algılanan örgütsel destek, örgütlerin çalışanların motivasyonunun artırılmasına yönelik çalışmalar bağlamında sosyal değişim teorisine dayandırımaktadır (Settoon, vd., 1996, Rhoades ve Eisenberger, 2002, Loi vd., 2006). Sosyal değişim teorisi 1964 yılında Blau tarafından geliştirilmiştir. Bateman ve Organ' a (1983) göre sosyal değişim teorisi; belirli durumlarda insanların kendilerine fayda getireceğini düşündükleri birey ya da bireylere karşı olumlu karşılık verme eğiliminde olduğunu ifade etmektedir. Bu durum örgüt için düşünüldüğünde; örgütler çalışanlarının mutluluğu ve iyiliği için bir şeyler yaptığında ve bunu çalışanın doğru algılamasına özen gösterdiğinde sosyal değişimin başlayacağı ifade edilmektedir (Allen vd., 2003: 102, Rhoades ve Eisenberger, 2002: 703). Bu çerçevede örgütsel destek; örgütün çalışanın katılımına özen göstermesi, onun iyiliğini istediğinin, onu önemsediğini hissettirmesinin ve bunu da gönüllü yaptığının çalışan tarafından algılaması olarak ifade edilmektedir (Eisenberger vd., 1986, 500). Stres araştırmacılar tarafından bir organizmanın herhangi bir olay veya duruma karşı verdiği sıra dışı tepki (Selye, 1976, 1); bireyden kaynaklanan, bireyin dayanma gücünü aşan ve bireyin kendini tehdit ettiğini düşündüğü ilişkilerin toplamı (Lazarus, 1985: 1421); bireyin duygu ve düşünce süreçlerinde veya bireyin fiziki ortamında çevresi ile baş edebilme gücünü tehdit eden gerilim durumu (Davis, 1982: 83) şeklinde farklı şekillerde tanımlanmıştır. Bireylerin çalışma ortamında yaşadıkları stres ise iş stresi olarak ifade edilmektedir. İ̧̧ stresi; bireyin kendisi, işin niteliği ve iş dışında gerçekleşen faktörlerin etkisinden dolayı çalışanın iş ortamında hissettiği gerilim durumu olarak ifade edilmektedir (Turunç ve Çelik, 2010: 186). Cinsiyete dayalı iş ayrımının ilk olarak ev hayatında ortaya çıktığı söylenebilir. Kriefting ve Berger (1979) yaptıkları çalışmada kadın işi - erkek işi diye bir ayrımın ortaya çıkma sebebini; kadın çalışanın işgücü piyasasına erkek çalışandan sonra girmesi ve kadınlar için tanımlanan işleri yapmak durumunda kalmaları şeklinde ifade etmiştir. Kadınlar genel olarak toplumun onlar için seçtiği rolleri yerine getirebilecekleri öğretmenlik, sekreterlik, hemşirelik gibi meslek gruplarını tercih etmekte iken, inşaat, müfettişlik, mühendislik gibi meslek gruplarını tercih etmemektedirler. Sehields (1987) yaptığı çalışmaya göre toplumun yönlendirmesiyle ortaya çıkan cinsiyete bağlı olarak işlerin belirlenmesi; ilk olarak meslek seçimine sonrasında, işe alma aşamasına hatta kadının çalışma yaşamının bütününe yansıyarak kadının yaşamını olumsuz etkileyeceği ifade edilmektedir. Bu çalışmada yapılmak istenen toplumun erkek işi olarak algıladığı fakat kadınların çalıştığı bir iş ortamında algılanan örgütsel destek ile iş stresi arasındaki ilişkiyi incelemektir. Algılanan örgütsel destek ile iş stres arasındaki ilişkiyi inceleyen çalışmalara bakıldığında negatif yönlü ilişki ve tepkilerin olduğu tespit edilmiştir (Eisenberger vd., 2004, George vd., 1993, Armstrong ve Griffin, 2004, Rhoades ve Eisenberger, 2002 ). George ve arkadaşlarının yaptığı (1993) araştırma sonuçlarına göre; stresli durumlarda çalışanın algıladığı örgütsel desteğin, maddi ve manevi olarak bireye yarar sağlayıp psikolojik gerginliğini ortadan kaldırdığı tespit edilmiştir. Farklı bir araştırmada algılanan örgütsel destek ile iş stresi sonucunda meydana gelen kaygı, bitkinlik, baş ağrısı ve psikolojik çöküntü değişkenleri arasında negatif yönlü ilişkilerin olduğu tespit edilmiştir (Eisenberger vd., 2004:213). Bir diğer çalışmada da benzer sonuçlarla örgütsel desteğin iş stresini azaltmada büyük etkiye sahip olduğu sonucuna ulaşılmıştır (Armstrong ve Griffin, 2004: 577-592). Bunlara ek olarak çalışan tarafından algılanan örgütsel desteğin stresin oluşmasına etkisi olan psikolojik ve psikometrik faktörleri azaltarak yok ettiğini ifade eden çalışmalar da mevcuttur (Rhoades ve Eisenberger, 2002:701). Yapılan çalışmalar algılanan örgütsel destek ile iş stresi arasında anlamlı ilişkilerin olduğu yönündedir. Fakat çalışmaların sonuçları uygulamasının yapıldığı ülkeye ve meslek gruplarına göre farklıık 
gösterebilmektedir. Bu çalışmayı diğerlerinden farklı kılacak olan iki unsur bulunmaktadır. Bunların ilki araştırmanın yapıldığı örneklem; ikincisi ise, veri toplama ve analizinde kullanılacak yöntemlerin nitel araştırmaya dayanmasıdır.

\section{VERI VE YÖNTEM}

Araştırmanın temel amacı erkek egemen mesleklerde çalışan kadınların algıladıkları örgütsel destek algısının ne olduğu ve bu algının iş stresi ile arasındaki ilişkiyi tespit etmektir. Amaç doğrultusunda çalışmanın araştırma soruları aşağıdaki gibidir.

Araştırma Sorusu 1: Erkek egemen mesleklerde çalışan kadınlar örgütsel desteği nasıl algılamaktadır?

Araştırma Sorusu 2: Erkek egemen mesleklerde çalışan kadınların algıladığı örgütsel destek ile iş stresi arasında bir ilişki var mıdır?

Araştırmanının evrenini, Kütahya illinde bulunan ve özel sektörde çalışan kadın mühendisler oluşturmaktadır. Araştırmanın amacına ulaşılabilmesi için evren belirlenirken erkek işi olarak ifade edilen mühendislik mesleğinde olan kadın çalışanlar özellikle tercih edilmiştir. Kamu sektörü yerine özel sektör tercih edilme nedeni ise; örgütün çalışana karşı destekleyici davranıp davranmadığının en çok hissedildiği, yönetici ve çalışanın birebir ilişkide olma durumunun kamu sektörüne göre daha fazla olmasıdır. Araştırmada nitel araştırma yöntemlerinden içerik ve betimleme analizlerinden faydalanıımıştır. Araştırmanın örneklemi ise, nitel araştırma yöntemlerinde kullanılan amaçlı örnekleme olarak adlandırılan örnekleme türüdür. Amaçlı örnekleme türü; belirli bir amaçla veya odaklanılan konuyla ilgili olarak örneklemin önceden düşünülüp belirlenmesidir (Punch, 2014: 183). Bu örnekleme türünün seçilmesindeki amaç; yapılacak çalışmanın konusunun ve bu konuya yönelik çalışma evreninin önceden belirlenmesidir. Araştırma verilerinin toplanmasında; nitel araştırmada yer alan veri toplama yöntemlerinden soru formu yardımıyla veriler elde edilmiştir. Soru formu oluşturulurken; araştırmanın konusunu oluşturan kavramlara yönelik okumalar yapılmış ve sonrasında nitel araştırmalar ile ilgili araştırmalar yapan iki uzmandan soruların uygunluğuna yönelik görüş alınmıştır. Illk oluşturulan soru formunda algılanan örgütsel desteğe ilişkin 20, iş stresine ilişkin 17, mühendisliğin erkek işi olduğuna yönelik algıya ilişkin 15 soru oluşturulmuştur. Uzman görüşü için görüşülen araştırmacılarla yapılan görüşme sonucunda sorular tartışılmış, sorunlu ifadeler, aynı anlam taşıyan ifadeler çıkarılarak kalan sorular açıklayıcı bir şekilde düzenlenmiş ve son halini almıştır. Araştırmanın soruları giriş bölümü, örgütsel destek algısının açığa çıkarılmasına yönelik sorular, iş stresinin açığa çıkarılmasına yönelik sorular ve mühendisliğin bir erkek işi olduğu algısına yönelik sorular olmak üzere dört bölümden oluşan bir soru formundan oluşmaktadır. Soru formunun giriş bölümü çalışanın demografik özelliklerine yönelik sorular 6 sorudan, örgütsel destek algısının açığa çıkarılmasına yönelik sorular 9 sorudan, iş stresinin açığa çıkarılmasına yönelik sorular 10 sorudan ve mühendisliğin bir erkek işi olduğu algısına yönelik sorular 3 sorudan oluşmaktadır. Oluşturulan soru formu halen çalışmakta olan 30 kadın mühendis çalışana ulaştırıımıştır. Zaman kısıtının olması nedeniyle geri dönüş sağlayan 16 kadın mühendisin cevapları ile veriler analiz edilmiştir. Çalışmanın geçerlilik ve güvenilirliği için bulgularda katılımcı görüşlerine yer verilerek içsel geçerlilik, araştırma sonuçlarının analizi aşamasında konuyla ilgili alanında çalışmalar yapmış iki uzaman tarafından görüş alınarak dışsal geçerlilik sağlanmaya çalışılmıştır.

\section{BULGULAR VE TARTIŞMA}

On altı katılımcıdan elde edilen veriler toplam olarak 64 sayfalık metin oluşmuştur. 64 sayfalık veri araştırmacı tarafından dikkatlice okunmuş ve metin özünde ne ifade ettiği anlaşılmaya çalışılmıştır. Bunun sonrasında açık kodlama aşamasına geçilerek veri seti başa dönülerek tekrar okunmuştur. íkinci okumada anlamlı bulunan ifadeler işaretlenerek kısa notlar (birimler) alınmıştır. İkinci okumanın sonucunda ortaya çıkan kısa notlar (birimler) belirgin hale getirilerek veri setleri arasında kıyaslama yapılmıştır ve açık kodlama işleminin sonuna gelinmiştir. Açık kodlama işleminden sonra eksenel kodlama işlemine geçilmiştir. Açık kodlama işleminde elde edilen kodlar bu aşamada belirli kategoriler altında toparlanmıştır. Eksenel kodlama aşamasının bitmesi ile son aşama olan seçici kodlama aşamasına geçilmiştir. Bu aşama temaların oluşturulduğu aşamayı ifade etmektedir. Temalar soru formu bölümleriyle ilişkilendirilerek ve kavramların literatürdeki karşılıkları düşünülerek oluşturulmuştur. Analiz sonucunda toplam olarak 70 kod, 6 kategori ve 3 tema oluşmuştur.

Tablo 1: Katılımcıların Demografik Özellikleri

\begin{tabular}{|l|c|l|l|l|c|c|}
\hline & Yaş & $\begin{array}{l}\text { Medeni } \\
\text { Durum }\end{array}$ & Eğitim & Gelir & $\begin{array}{l}\text { Meslekte } \\
\text { Çalışma Yılı }\end{array}$ & $\begin{array}{l}\text { Kurumda } \\
\text { Çalışma Yılı }\end{array}$ \\
\hline Katııımcı 1 & 25 & Bekar & Yüksek Lisans & $2000 \mathrm{TL}$ & $2,5 \mathrm{yıl}$ & $1 \mathrm{yıl}$ \\
\hline Katılımcı 2 & 27 & Bekar & Yüksek Lisans & $1600 \mathrm{TL}$ & $3 \mathrm{yıl}$ & $1 \mathrm{yıl}$ \\
\hline Katılımcı 3 & 26 & Evli & Lisans & $2000 \mathrm{TL}$ & $3 \mathrm{ay}$ & 3 ay \\
\hline Katııımcı 4 & 24 & Bekar & Lisans & $1500 \mathrm{TL}$ & $1,5 \mathrm{yıl}$ & $1,5 \mathrm{yıl}$ \\
\hline Katılımcı 5 & 27 & Evli & Lisans & $1600 \mathrm{TL}$ & $2,5 \mathrm{yıl}$ & 2 ay \\
\hline Katılımcı 6 & 24 & Bekar & Yüksek Lisans & $1600 \mathrm{TL}$ & $1 \mathrm{yıl}$ & $1 \mathrm{yıl}$ \\
\hline Katılımcı 7 & 26 & Bekar & Lisans & $2000 \mathrm{TL}$ & $2 \mathrm{yıl}$ & 3 ay \\
\hline
\end{tabular}




\begin{tabular}{|l|c|c|c|c|c|c|}
\hline Katılımcı 8 & 26 & Evli & Lisans & $2000 \mathrm{TL}$ & $3,5 \mathrm{yıl}$ & $1,5 \mathrm{yıl}$ \\
\hline Katılımcı 9 & 24 & Bekar & Lisans & $2000 \mathrm{TL}$ & $1,5 \mathrm{yıl}$ & $1,5 \mathrm{yıl}$ \\
\hline Katılımcı 10 & 24 & Bekar & Lisans & $2000 \mathrm{TL}$ & $10 \mathrm{ay}$ & $10 \mathrm{ay}$ \\
\hline Katılımcı 11 & 30 & Evli & Doktora & $7000 \mathrm{TL}$ & $6 \mathrm{yıl}$ & $5,5 \mathrm{yıl}$ \\
\hline Katılımcı 12 & 32 & Evli & Lisans & $8000 \mathrm{TL}$ & $8 \mathrm{yıl}$ & $7 \mathrm{yıl}$ \\
\hline Katılımcı 13 & 23 & Bekar & Lisans & $1600 \mathrm{TL}$ & $8 \mathrm{ay}$ & $8 \mathrm{ay}$ \\
\hline Katılımcı 14 & 25 & Bekar & Yüksek Lisans & $2000 \mathrm{TL}$ & $2 \mathrm{yıl}$ & $1,5 \mathrm{yıl}$ \\
\hline Katılımcı 15 & 27 & Evli & Lisans & $2500 \mathrm{TL}$ & $4 \mathrm{yıl}$ & $7 \mathrm{ay}$ \\
\hline Katılımcı 16 & 29 & Evli & Lisans & $4000 \mathrm{TL}$ & $5 \mathrm{yıl}$ & $3 \mathrm{yıl}$ \\
\hline
\end{tabular}

Tabloda görüldüğü gibi araştırmaya katılan on altı kadın katılımcının yaşları 23 ile 32 asında değişmektedir. Katıımcıların eğitim düzeyi genel olarak lisans seviyesinde ve aralarından biri doktora düzeyinde eğitim almıştır. Gelir düzeyi ortama olarak 2000 TL civarındadır ve en yüksek gelire sahip olan katılımcının geliri 8000 TL dir.

Tablo 2: Kodlar ve Kategoriler

\begin{tabular}{|c|c|}
\hline Kategori 1: Algılanan Olumlu Duygu & İşi eve taşıma \\
\hline Teşekkür almak & İşteki sorunların tüm zamanı öldürmesi \\
\hline Yatığım işin faydalı olduğunun hissettirilmesi & İşin çalışanı asabi biri haline getirmesi \\
\hline Fiziksel, psikolojik ve sosyal sorunlarımla ilgilenilmesi & Ruhsal sorunlar \\
\hline Tecrübelilerin tecrübesizlere yardım etmesi & Halsizlik \\
\hline Öz yeterliliğimin artması için desteklenmem & İsteksizlik \\
\hline Fikirlerimin dikkate alınması & Depresyon \\
\hline Takdir edilmek & Kategori 4: Kontrol edilebilen iş stresi \\
\hline Terfi alacağıma dair olan inancım & Denetimlerin işi iyi yapma derecesini artırması \\
\hline Sorunlarımı üstlerimle paylaşabilme olanağı & Yönetici beklentisinin çalışanı motive etmesi \\
\hline Üst ve astlarım tarafından dinlenmem & İşin günün güzel geçmesine neden olması \\
\hline Yanlış uygulamalar için özür dilenmesi & İş anında yöneticimin destek vermesi \\
\hline Hatalarımın tölere edilmesi & Yapılan toplantıların çalışanı planlı biri haline getirmesi \\
\hline Önerilerimin dikkate alınması & Kategori 5: Mühendislik mesleğinin gerekleri \\
\hline Oy kullanma hakkımın olması & Yaratıcı olmak \\
\hline Örgüt içi adaletin olması & Etkileyici olmak \\
\hline Ücret, yan ödeme ve ödüllerin dağıtımında adil olunması & Resmin bütününü görmek \\
\hline Kategori 2: Algılanan Olumsuz Duygu & Analitik düşünmek \\
\hline Çabamın fark edilmemesi & Hızlı ve doğru kararı verebilmek \\
\hline Tecrübesizliğimin yüzüme vurulması & Düzen ve tertipli olma \\
\hline Hatalarımın sert bir dille uyarılması & Sorumluluk sahibi olma \\
\hline İyiliğimin düşünülmemesi & Sayısal zekaya sahip olma \\
\hline Çalışma saatlerinin esnetilemez oluşu & Kriz yönetiminde başarılı \\
\hline Fikirlerimin önemsenmemesi & Kararlı \\
\hline Ücret eşitsizliğinin olması & Planlı \\
\hline Takdir yerine tektir edilmek & İleriyi görebilen \\
\hline Başarılarımın göz ardı edilmesi & İş bitirme odaklı \\
\hline Sorunlarımı üstlerimle paylaşamamam & İkna kabiliyeti \\
\hline $\begin{array}{l}\text { Şirketin bizlerden daha önemli olduğunun sıklıkla } \\
\text { hissettirilmesi }\end{array}$ & Kategori 6: Kadın işi olarak mühendislik \\
\hline İşin benim için anlamlılığının umursanmaması & Bu meslek erkek ve kadın için eşit özelliklerde \\
\hline Kategori 3: Kontrol edilemeyen iş stresi & Bu meslek kadın işi \\
\hline İşin günün çirkin geçmesine neden olması & Tertip ve düzen gerektirmesi açısından kadın işi \\
\hline Stres & Ehliyeti olan her kadın yapabilir \\
\hline Baş ağrısı & İkna kabiliyeti kadınlarda erkeklerden daha iyi olması \\
\hline Yorgunluk & Kendinden emin \\
\hline Psikolojik bozukluk & Yapacağı işi bilen kadınlar var \\
\hline Sosyal hayata zaman ayıramama & Her mühendislik dalı erkek işi değildir \\
\hline Toplantıların gergin geçmesi & Kendini geliştiren her birey mühendis olabilir \\
\hline
\end{tabular}

Tabloda görüldüğü gibi araştırma sonucunda toplam 6 kategori oluşmuştur. Bu kategorilerin oluşturduğu 3 tanede tema bulunmaktadır. Aşağıdaki tabloda kategorilerin oluşturduğu temalar yer almaktadır. 
Tablo 3: Temalar

\begin{tabular}{|l|l|l|}
\hline Tema 1: Örgütsel Destek & Tema 2: İş Stresi & Tema 3: Mühendislik \\
\hline Algılanan Olumlu Duygu & Kontrol edilemeyen iş stresi & Mühendislik mesleğinin gerekleri \\
\hline Algılanan Olumsuz Duygu & Kontrol edilebilen iş stresi & Kadın işi olarak mühendislik \\
\hline
\end{tabular}

Tabloya göre araştırma sonucunda ortaya çıkan temalar örgütsel destek, iş stresi ve mühendislik olmak üzere üç tanedir. Bu temalar algılanan olumlu duygu, algılanan olumsuz duygu, kontrol edilemeyen iş stresi, kontrol edilebilen iş stresi, mühendislik mesleğinin gerekleri ve kadın işi olarak mühendislik olmak üzere altı kategoriden oluşmaktadır. Araştırmanın amacını ortaya çıkarmaya yönelik katılımcı görüşlerine çalışmanın bu kısmından sonra yer verilecektir.

Katılımcıların algıladıkları örgütsel desteğin ortaya çıkarılmasına yönelik olarak dokuz tane soru sorulmuş ve katılımcıların 12 tanesi olumlu manada örgütlerinden maddi ve manevi destek aldıklarını 4 tanesi ise örgütsel desteğin olmadığını ifade etmişlerdir. Aşağıda bu iki görüşü de destekleyen iki adet katılımcı görüşüne yer verilmiştir;

$\checkmark \quad$ Katılımcı 1: Çalıştığım kurumun faaliyet alanı hizmet sektörü olduğu için insanlar ile iletişime önem vermektedir. Müşterilerine karşı göstermiş olduğu hassasiyeti çalışanlarına (bana) karşıda göstermektedir. Benim sağlamış olduğum katkıyı bana hissettirerek benim motivasyonumu yükseltmekteler. Buda dolaylı olarak müşterilere karşı benim hassasiyetimi artırmaktadır. Müşterilerle sağlıklı ve hoşgörülü iletişimim hizmetimizi satmama ve kurumuma katkı sağlamama neden oluyor.

$\checkmark \quad$ Katılımc 6: Çalıştığım kurum benim fikirlerime önem vermiyor ve benim kararlara katılmamı sağlamıyor. Aynı zamanda kurumumun yararını düşünerek yaptığım olumlu eleştirileri göz ardı ederek kendi doğrularını yapmaya devam ediyor.

Katılımcıların çalıştıkları iş ve meslekle ilgili olarak iş stresi yaşayıp yaşamadıklarına yönelik olarak on tane soru sorulmuş ve katılımcıların 9 tanesi iş stresini yaşadığı 7 tanesi ise iş stresini yaşamadığını ifade etmişlerdir. Aşağıda bu iki görüşü de destekleyen iki adet katılımcı görüşüne yer verilmiştir;

$\checkmark \quad$ Katılımc 11: İşimle ilgili yaşadığım sorunlar bende sosyal tatminsizlik, özgüven eksikliği, halsizlik, iştahsızlık, yoğun başağrısı gibi sorunlara neden oluyor.

$\checkmark \quad$ Katılımcı 12: Yöneticilerimin yaptığı denetimler şirketin mevcut durumunu koruması ve stratejik hedeflerine ulaşmasında önemlidir. Yapılan denetimler benim bu hedefe ulaşmada yapacağım hataları minimuma düşürerek işimi daha iyi yapmamı sağlıyor.

Katılımcılara mühendislik mesleğinde bulunması gereken özellikler ve mühendislik mesleğinin bir erkek işi olup olmadığına yönelik üç tane soru sorulmuş ve katılımcıların 15 tanesi mühendisliğin hem kadın hem erkek işi olduğunu ifade etmişlerdir. Bir tane katııımcı ise mühendisliğin erkek işi olduğunu ifade etmiştir. Aşağıda bu iki görüşü de destekleyen iki adet katılımcı görüşüne yer verilmiştir;

$\checkmark \quad$ Katılımcı 8: Mesleğimizi seçerken maalesef ülke olarak yaş anlamında çok erken davranıyoruz. Mesleğimi seviyorum ancak zaman zaman bayan içgüdüsü ile başka sektörlerde hayal kurma durumum oluyor

$\checkmark \quad$ Katılımcı 5: Kesinlikle cinsiyet ayrımı olmayan bir meslek. Ehliyetin varsa, kendini ifade edebiliyorsan, ikna kabiliyetin yüksek ve yapacağın işi biliyorsan gayet bir erkekten daha başarılı olabilirsin.

Katılımcıların verdiği cevaplara bakıldı̆ıında örgütsel desteği algılayan 12 katılımcının 7 tanesinin iş stresini yaşamadığı, 5 tanesinin ise iş stresini yaşadığı tespit edilmiştir. Kurumundan örgütsel desteği algılamayan 4 katılımcının ise iş stresini algılayanlara göre daha çok yaşadığı tespit edilmiştir.

\section{SONUC}

Bu çalışma erkek egemen mesleklerde çalışan kadınların algıladıkları örgütsel destek ile iş stresi arasındaki ilişkiyi nitel veri toplama ve analiz etme yöntemleriyle tespit etmeyi amaçlamıştır. Çalışmada ilk olarak algılanan örgütsel destek, iş stresi ve erkek işi-kadın işi kavramları hakkında bilgi verilmiş ve bu kavramlar hakkındaki ilişkilerden bahsedilmiştir. Sonrasında araştırmanın evreni, örneklemi, araştırma soruları ve bulguları hakkında bilgi verilmiştir. Günümüz rekabet ortamı ve yaşam şartlarının zorlaşması göz önünde bulundurulduğunda örgütlerin çalışanlarına sağladıkları imkan çalışanların kuruma karşı duygusal bağlılıklarını ve yaşam kalitelerini artırıı bir faktör haline gelmektedir. Bu bağlamda psikolojik ve fizyolojik olarak daha narin olan kadınların iş yaşamında örgütleri tarafından algıladıkları destek daha anlamlı hale gelmektedir.

Çalışma Kütahya Iili Merkez İlçesi'nde özel sektörde çalışan kadın çalışanlar üzerinde yapılmıştır. Çalışmanın özel sektör seçilme gerekçesi rekabet, yüksek performans beklentisi ve yönetici-çalışan ilişkisin yakın olmasıdır. Özellikle kadın mühendislerin seçilmesi ise erkek işi olarak ifade edilen mühendislik mesleğinde algılanan örgütsel desteğin daha anlamlı olacağı düşüncesidir. 
Çalışmanın analiz kısmında ilk olarak içerik analizine dayalı frekans analizleri yapılmıştı. Katılımcıların demografik özelliklerine yer verildikten sonra üç aşamalı gerçekleşen kod, kategori ve tema çalışması yapılmıştır. Bu çalışma sonucunda 70 kod, 6 kategori ve 3 tema oluşmuştur.

Çalışmanın araştırma sorularına cevap betimsel analiz yardımıyla katılımcı görüşlerine yer verilerek aranmıştır. Katılımcı görüşlerine göre örgütsel desteği olumlu manada algılayan 12 katılımcının, iş stresini algılayan 9 katılımcının, mühendisliği bir erkek işi olarak algılayan sadece 1 katılımcının ve örgütsel desteği algılayan 12 katılımcıdan 7 tanesinin iş stresini algılamadığı, 5 katııımcının ise algıladığı sonucuna ulaşıımıştır.

\section{KAYNAKLAR}

Allen, D., Shore, L.M., Griffeth, R.W., (2003). The Role of Perceived Organizational Support and Supportive Human Resource Practices in The Turnover Process. Journal of Management. vol. 29, p. 99-118.

Armstrong, G. S., Griffin, M. L., (2004), Does the Job Matter? Comparing Correlates of Stress Among Treatment and Correctional Staff in Prisons. Journal of Criminal Justice. vol. 32, p. $577-592$.

Bateman, T. S., Organ, D. W., (1983). Job Satisfaction and the Good Soldier: The Relationship Between Affect and Employee Citizenship. Academy of Management Journal. vol. 26, no. 4, p. 587-595.

Blau, P., (1964). Exchange and Power in Social Life. New York: Wiley.

Davis, K., (1982). İşletmelerde İnsan Davranışı. (Çev. Kemal TOSUN vd.) İstanbul Üniversitesi İşletme Fakültesi Yayını. No. 199. ísTANBUL.

Eisenberger, R., Aselage, J., Sucharski , I. L., Jones, J. R., (2004). Perceived Organizational Support. In: J. Coyle-Shapiro, L. Shore, S. Taylor, L. Tetrick (Eds.). The Employment Relationship: Examining Psychological and Contextual Perspectives. USA: Oxford University Press.

Eisenberger, R., Huntington R., Hutchison S., Sowa, D., (1986). Perceived Organizational Support. Journal of Applied Psychology, vol. 7, p. 500-507.

George, J. M., Reed, T. F., Ballard, K. A., Colin, J., Fielding, J. (1993). Contact With Aids Patients As A Source Of Work-Related Distress-Effects of Organizational And Social Support. Academy of Management Journal, vol. 36, no. 1, p. 157-71.

Kriefting, L., Berger, P., (1979). Masculinity-Feminine Perceptions of Job Requirements and Their Relationship to Job-Sex Stereotypes. Journal of Vocational Behavior. vol. 164, p. 164-174.

Lazarus, A.A., (1985). Setting the Record Straight. American Psychologist. vol. 40, no. 12, s.1418- 1419.

Mcmillan, K., Albrecht, S., (2010). Measuring Social Exchange Constructs in Organizations. Communication Methods And Measures. vol. 4, no. 3, p. 201-220.

Punch, K.F., (2014). Sosyal Araştırmalara Giriş: Nicel ve Nitel Yaklaşımlar. Siyasal Kitabevi.

Rhoades, L., Eisenberger, R., (2002). Perceived Organizational Support: A Review of the Literature. Journal of Applied Psychology. vol. 87, p. 698-714.

Selye, H., (1976), The Stres of Life. New York: McGraw Hill.

Settoon, R. P., Bennett, N., Liden, R. C., (1996). Social Exchange in Organizations: Perceived Organizational Support, Leader-Member Exchange, and Employee Reciprocity. Journal of Applied Psychology. vol. 81, p. 219-227.

Shields, N. G., (1987), Female Labor and Education. Economics of Education: Research and Studies. p. 121-129.

Turunç, Ö.,Çelik, M. (2010), Çalışanların Algıladıkları Örgütsel Destek ve İş Stresinin Örgütsel Özdeşleşme ve İş Performansına Etkisi. Yönetim ve Ekonomi Dergisi. cilt. 17, sayı. 2, s. 183-206. 